\title{
Correction to: MJO teleconnections to crop growing seasons
}

\author{
Weston Anderson ${ }^{1}\left[\right.$ (D $\cdot$ Ángel G. Muñoz ${ }^{1} \cdot$ Lisa Goddard $^{1} \cdot$ Walter Baethgen $^{1} \cdot$ Xandre Chourio $^{1}$
}

Published online: 26 February 2020

(c) The Author(s) 2020

\section{Correction to: Climate Dynamics (2020) 54:2203-2219 \\ https://doi.org/10.1007/s00382-019-05109-0}

In the original version of the article contained errors in the panel labels of Figs. 3 and 4 and captions of Figs. 3 and 4 with respect to the panels in the top row. The correct Figs. 3 and 4 and captions for Figs. 3 and 4 is given in this correction article. 

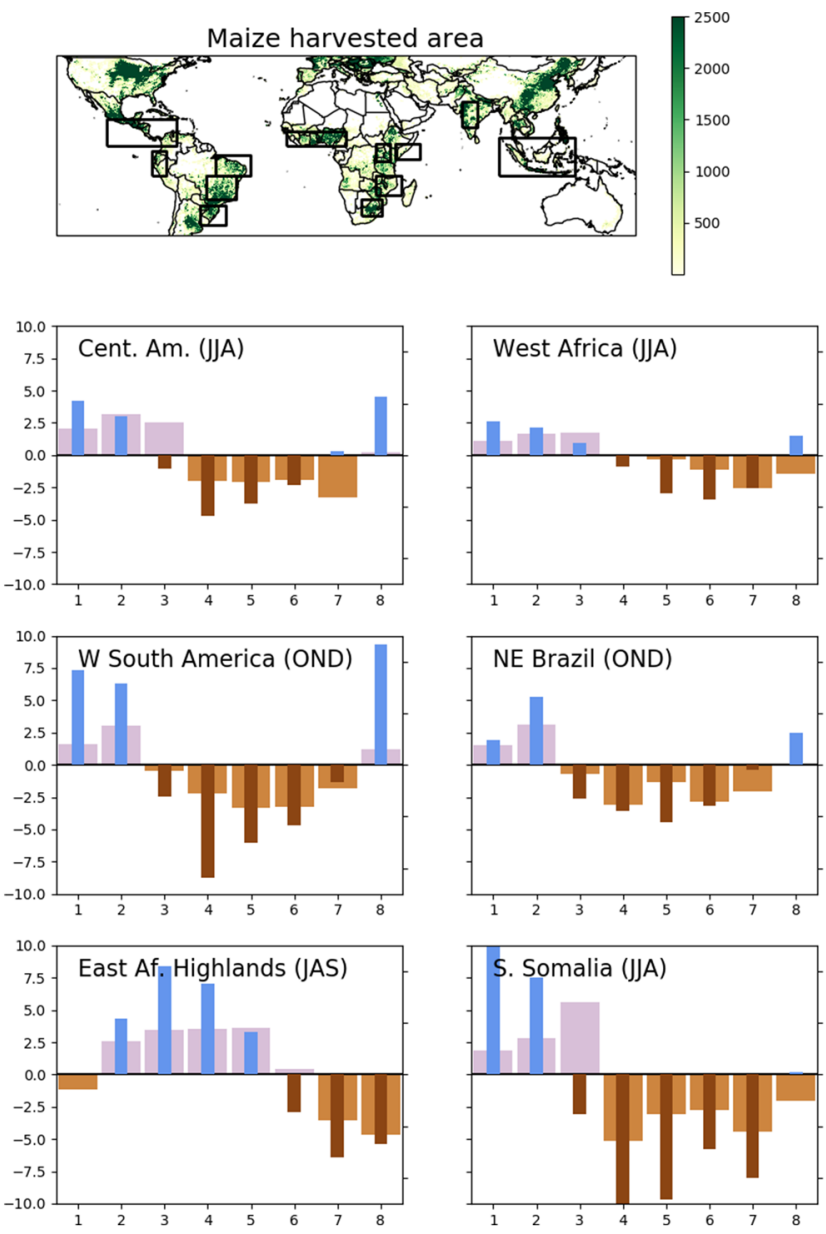

Fig. 3 Relative strength of MJO teleconnections during the maize growing season. Top row: maize harvested area (left panel) and approximate maize harvest date (right panel). Bottom three rows: precipitation (thin blue and brown bars) and soil moisture (thick purple and brown bars) anomalies during each MJO phase relative
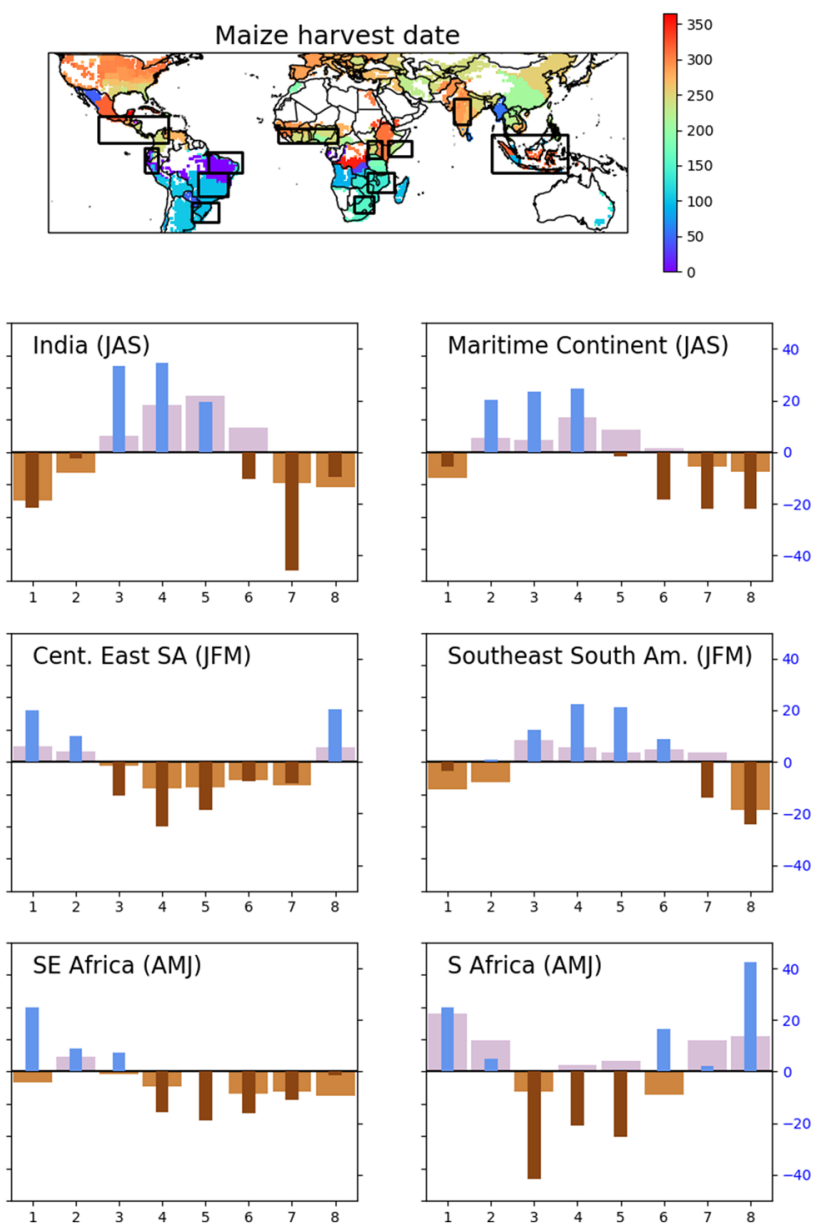

to an average day when MJO is inactive during the growing season. Regions defined by boxes shown in the top row. A precipitation bar in a given phase with a value of $20 \%$, for example, indicates that on average precipitation during that phase is $20 \%$ greater compared to an average day in the growing season when the MJO is inactive 

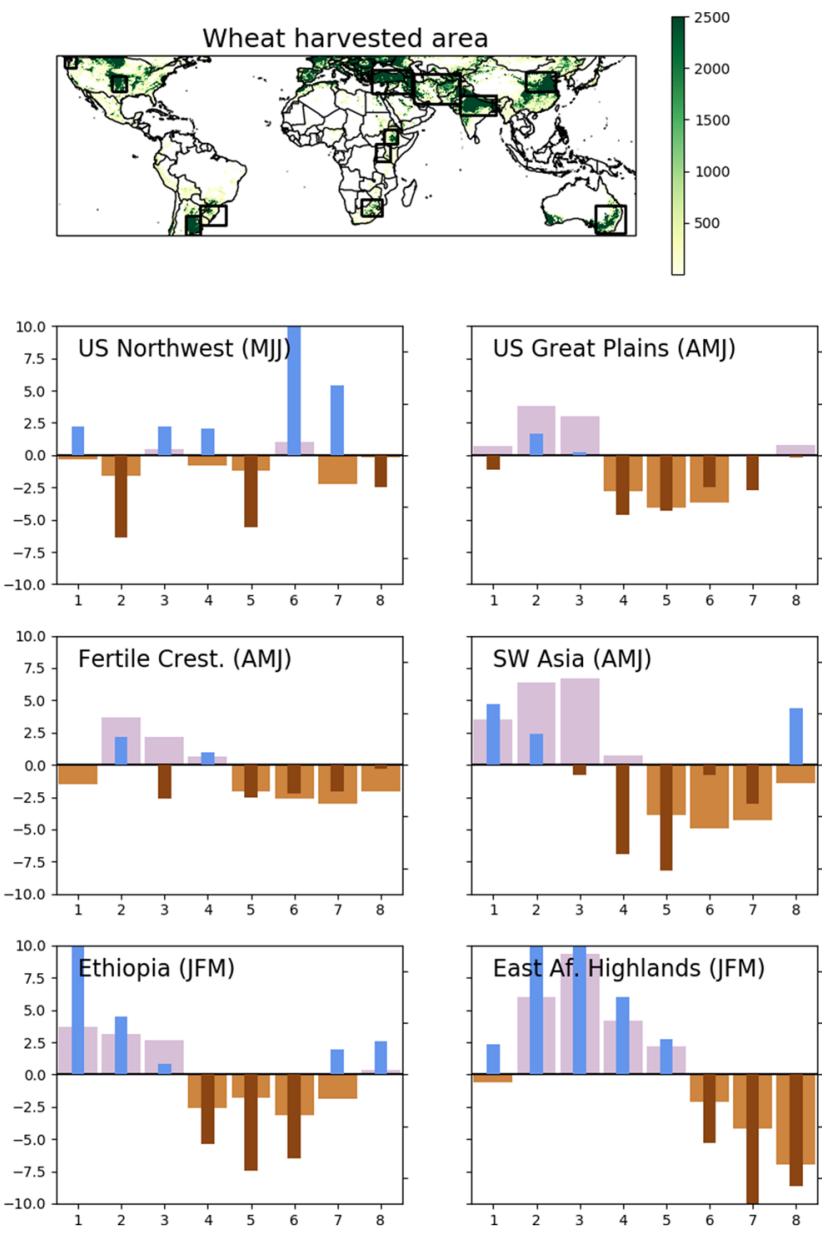

Fig. 4 Relative strength of MJO teleconnections during the wheat growing season. Top row: wheat harvested area (left panel) and approximate wheat harvest date (right panel). Bottom three rows: precipitation (thin blue and brown bars) and soil moisture (thick purple and brown bars) anomalies during each MJO phase relative

Publisher's Note Springer Nature remains neutral with regard to jurisdictional claims in published maps and institutional affiliations.
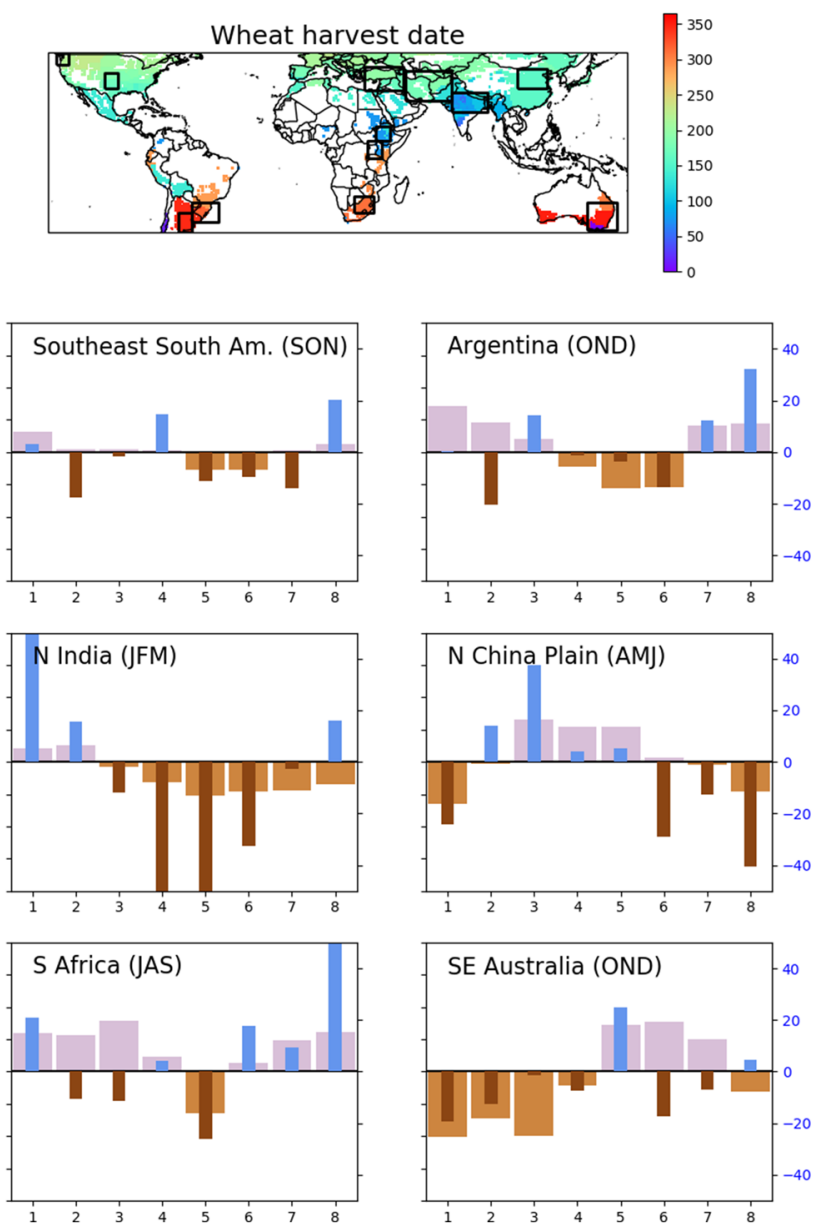

to an average day when MJO is inactive during the growing season. Regions defined by boxes shown in the top row. A precipitation bar in a given phase with a value of $20 \%$, for example, indicates that on average precipitation during that phase is $20 \%$ greater compared to an average day in the growing season when the MJO is inactive 